\title{
Transient High-Glucose Stimulation Induces Persistent Inflammatory Factor Secretion from Rat Glomerular Mesangial Cells via an Epigenetic Mechanism
}

\author{
Deng Yunlei Fan Qiuling Wang Xu Zhao Qianwen Cao Xu \\ Xu Li Wang Lining \\ Department of Nephrology, the First Hospital of China Medical University, Shenyang, China
}

\section{Key Words}

Diabetic Nephropathy $\cdot$ Histone Methylation $\cdot$ Metabolic Memory $\cdot$ Inflammatory Factors $•$ Epigenetics

\begin{abstract}
Background/Aims: Diabetic nephropathy is the one of the most serious microvascular complications of diabetes mellitus, and "metabolic memory" plays a vital role in the development of diabetic complications. To investigate the effect of epigenetics on metabolic memory, we analyzed the impact of transient high-glucose stimulation on the secretion of inflammatory factors from rat glomerular mesangial cells. Methods: Rat glomerular mesangial cells (HBZY-1) were divided into three groups: high-glucose group ( $25 \mathrm{mM}$ glucose), hypertonic group (5.5 mM glucose+19.5 mM mannitol), and normal-glucose control group (5.5 mM glucose). Mesangial cells were cultured in high-glucose, hypertonic, and normal-glucose media for $24 \mathrm{~h}$ and transitioned to normal-glucose culture for 24,48 , and $72 \mathrm{~h}$. Then, protein, mRNA, and supernatants were harvested. The expression of monomethylated H3K4 was determined by western blot analysis, and the expression of the NF- $\kappa B$ subunit p65 and histone methyltransferase set7/9 was determined by quantitative real-time PCR. The expression of monocyte chemoattractant protein 1 (MCP-1) and vascular cell adhesion molecule 1 (VCAM1) was detected by an enzyme-linked immunosorbent assay. Results: Compared with the control group, $\mathrm{H} 3 \mathrm{~K} 4 \mathrm{me} 1$ expression was upregulated after transient high-glucose stimulation, gradually downregulated in the following $48 \mathrm{~h}(P<0.05)$, and reached the level of the control group at $72 \mathrm{~h}(P>0.05)$. The expression of set7/9 was increased after $24 \mathrm{~h}$ of high-glucose stimulation and the following $24 \mathrm{~h}$ and $48 \mathrm{~h}(P<0.05)$; it then returned to the level of the control group at $72 \mathrm{~h}$. Compared with the control group, the increased expression of p65,
\end{abstract}


VCAM-1, and MCP-1 was sustained for at least $72 \mathrm{~h}$ in the high-glucose group. Conclusion: Transient high-glucose stimulation can induce the persistent secretion of inflammatory factors from rat glomerular mesangial cells via histone modification.

\section{Introduction}

(C) 2018 The Author(s)

Published by S. Karger AG, Basel

Diabetic nephropathy (DN) is the one of the most serious microvascular complications of diabetes mellitus; it has become the leading risk factor for the development of endstage renal disease $[1,2]$. However, the mechanism underlying the pathogenesis of DN is incompletely resolved, and there is no specific drug for the treatment and prevention of the development of DN, which has become a worldwide burden on public health. Recently, dysfunction of glomerular mesangial cells has been suggested to play a vital role in the pathogenesis of DN [3]_ENREF_3. Actually, even with strict control of plasma glucose, many diabetic patients eventually develop DN. This phenomenon indicates that the targeted organs might have suffered injury induced by hyperglycemia. Currently, sustained injury under normal glucose concentrations in diabetic patients is referred to as "metabolic memory" [4]. In fact, this phenomenon was been demonstrated in the Diabetes Control and Complications Trial/Epidemiology of Diabetes Interventions and Complications (DCCT/EDIC) study [5, 6]. In the DCCT/EDIC study, a reduction in the time-averaged mean levels of glycemia, measured as $\mathrm{HbA1c}$, was shown to decrease the risk of sustained retinopathy progression, the primary outcome of the study, by $73 \%$. However, for the entire study group, HbA1c explained less than $25 \%$ of the variation in the risk of developing this complication [7].

Studies have found that metabolic memory dwindles in cells such as vascular smooth muscle cells, retinal endothelial cells, and Schwann cells [8-12]. However, no studies have examined whether this phenomenon exists in renal parenchymal cells. To investigate whether transient high-glucose (HG) stimulation followed by a normal glucose concentration could induce a sustained release of inflammatory factors from glomerular mesangial cells and its relevance to histone methylation, we designed the present study.

\section{Materials and Methods}

\section{Cell culture and materials}

The rat mesangial cell line HBZY-1 was purchased from the China Center for Type Culture Collection (Wuhan, China) and cultured in low-glucose Dulbecco's modified Eagle's medium (DMEM; HyClone Technologies, Logan, UT) containing 10\% fetal bovine serum (HyClone Technologies). The cells were routinely cultured at $37^{\circ} \mathrm{C}$ and $5 \% \mathrm{CO}_{2}$ in saturated humidity. When the cells reached $90 \%$ confluence, they were assigned to three groups and eight subgroups: the normal-glucose (NG) group, in which the cells were incubated in $5.5 \mathrm{mmol} / \mathrm{L}$ D-glucose (Sigma-Aldrich, St. Louis, MO); the hypertonic control (HT) group, in which the cells were incubated in $5.5 \mathrm{mmol} / \mathrm{L}$ D-glucose DMEM + $19.5 \mathrm{mmol} / \mathrm{L}$ D-mannitol (Sigma-Aldrich); and the HG group, in which the cells were stimulated with $25 \mathrm{mmol} / \mathrm{L} \mathrm{D}$-glucose. All cells in the three groups were stimulated for $24 \mathrm{~h}$ and then cultured in $5.5 \mathrm{mmol} / \mathrm{L}$ D-glucose DMEM. At $0,24,48$, and $72 \mathrm{~h}$, the cells and their supernatants were collected.

Quantitative real-time PCR detection

Total RNA was extracted from the cells in each group using the TRIzol reagent (Invitrogen, Carlsbad, CA) and transcribed into cDNA by a PrimeScript ${ }^{\mathrm{TM}}$ RT reagent kit (Takara Bio, Inc., Kusatsu, Japan). All procedures were performed in accordance with the product instructions. The primer sequences used in the present study are listed in Table 1.
Table 1. Primers used for quantitative real-time PCR

\begin{tabular}{lcc}
\hline Gene & Primer sequence $\left(5^{\prime}-3^{\prime}\right)$ & Product size (bp) \\
\hline \multirow{2}{*}{ set7/9 } & AGGTTGACAGCAGGGATT & 148 \\
& CAGTTCGGAGAAGGGAGT & \\
NF-kB p65 & $\begin{array}{c}\text { GTGCAGCCTCTTCGTCCTC } \\
\text { GTGCACTACAGACGAGCCATT }\end{array}$ & 154 \\
GAPDH & CGTATCGGACGCCTGGTT & 124 \\
& CGTGGGTAGAGTCATACTGGAAC & \\
\hline
\end{tabular}




\section{Cellular Physiology Cell Physiol Biochem 2018;49:1747-1754

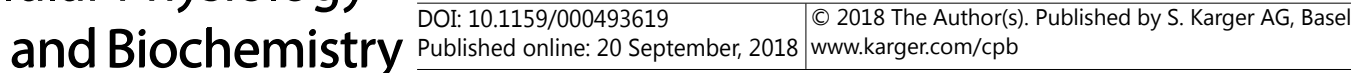 \\ Yunlei et al.: Transient High Glucose Induces Sustained Inflammation}

The following reaction conditions were used: predenaturation at $94^{\circ} \mathrm{C}$ for $5 \mathrm{~min}$, followed by 40 cycles of denaturation at $95^{\circ} \mathrm{C}$ for $10 \mathrm{~s}$, annealing at $60^{\circ} \mathrm{C}$ for $30 \mathrm{~s}$, and extension at $72^{\circ} \mathrm{C}$ for $30 \mathrm{~s}$. Glyceraldehyde 3-phosphate dehydrogenase (GAPDH) was used as an internal control. Relative mRNA expression was quantified through a comparison of the cycle threshold $(\mathrm{Ct})$ values. The experimental data were processed using the $2^{-\Delta \Delta \mathrm{Ct}}$ method: $\Delta \Delta \mathrm{Ct}=\left(\left[\mathrm{Ct}_{\text {target }}-\mathrm{Ct}_{\text {internal control }}\right]\right.$ of the experimental group $)-\left(\left[\mathrm{Ct}_{\text {target }}-\mathrm{Ct}_{\text {internal control }}\right]\right.$ of the normal control group). Each group was examined in triplicate.

\section{Western blotting}

Total protein was extracted from the cells in each group using a precooled RIPA lysis buffer containing protease inhibitors. Protein concentrations were determined using a Micro BCA Protein Kit. Approximately 30-50 $\mu \mathrm{g}$ total protein was separated using sodium dodecyl sulfate-polyacrylamide gel electrophoresis. Subsequently, the proteins were transferred onto a nitrocellulose membrane. The membrane was blocked in $3 \%$ bovine serum albumin at room temperature for $1 \mathrm{~h}$, followed by incubation with a primary antibody (anti-H3K4me1, 1:1000 dilution; Abcam, Cambridge, UK) for $4 \mathrm{~h}$ with slow shaking, and additional incubation at $4{ }^{\circ} \mathrm{C}$ overnight. GAPDH (1:2000 dilution; Proteintech, Chicago, IL) was used as an internal control. The membrane was washed 3 times with Tris-buffered saline containing Tween-20 (TBST) for $10 \mathrm{~min}$ and subsequently incubated with a secondary antibody (1:20000 dilution; Proteintech) at room temperature for $1 \mathrm{~h}$. After washing 3 times with TBST for $10 \mathrm{~min}$, the membrane was developed using an enhanced chemiluminescence solution and scanned. Semi-quantitative analysis was performed by ImageJ image analysis software (National Institutes of Health, Bethesda, MD).

\section{Enzyme-linked immunosorbent assay}

All procedures were performed strictly according to the instructions of the monocyte chemoattractant protein 1 (MCP-1) and vascular cell adhesion molecule 1 (VCAM-1) reagent kit (Horabio Co., Shanghai, China). The supernatants from each group of cells were collected, centrifuged at $1000 \mathrm{rpm}$ to remove the precipitate, and stored in a freezer at $-80^{\circ} \mathrm{C}$. All materials were equilibrated, and the reagents were prepared at room temperature $\left(18-25^{\circ} \mathrm{C}\right)$ prior to use; the standards were diluted into five serial dilutions on a concentration gradient. A total of $100 \mu \mathrm{L}$ deionized water was added to the blank well, while $50 \mu \mathrm{L}$ standard and $50 \mu \mathrm{L}$ streptomycin-horeseradish peroxidase (HRP) were added to the standard wells, and 40 $\mu \mathrm{L}$ cell supernatant, $50 \mu \mathrm{L}$ streptomycin-HRP, and $10 \mu \mathrm{L}$ anti-VCAM-1 antibody or anti-MCP- 1 antibody were added to the sample wells. All wells contained a total volume of $100 \mu \mathrm{L}$. The wells were covered with a film and incubated for $1 \mathrm{~h}$ at room temperature with gentle shaking. The solutions in the wells were discarded, and the plate was inverted and blotted against clean paper towels. Then, $300 \mu \mathrm{L}$ washing solution was added to each well, and the plate was allowed to stand for $30 \mathrm{~s}$ and then blotted against clean paper towels; this process was repeated 5 times. The plate was patted dry, and $50 \mu \mathrm{L}$ each of Assay Diluents A and B was added to each well. Then, the plate was incubated for $10 \mathrm{~min}$ at room temperature in the dark with gentle shaking. Finally, $50 \mu \mathrm{L}$ Stop Solution was added to each well, and after $15 \mathrm{~min}$, absorbance was read at $450 \mathrm{~nm}$.

\section{Statistical analysis}

All experiments were repeated at least three times independently. Quantitative data are presented as the mean \pm standard error of the mean $(\mathrm{x} \pm s$ ). Statistical analysis was performed using Statistical Package for Social Science (SPSS) 17.0 software (SPSS Inc., Chicago, IL). Pairwise comparisons were performed using the t-test. $P<0.05$ indicated that the observed difference was statistically significant.

\section{Results}

Transient HG stimulation upregulates the expression of the histone methyltransferase set7/9

Separately, HBZY-1 cells in the three groups were incubated in HG, HT, and NG culture media for $24 \mathrm{~h}$ and then in NG medium for 24, 48, and $72 \mathrm{~h}$ (Fig. 1). Compared with the NG and HT groups, set7/9 mRNA expression was increased in the HG group. When the mesangial cells in the HG group were transferred to the NG condition for 24 and $48 \mathrm{~h}$, the expression of set7/9 mRNA was consistently upregulated, and its expression level was higher than in 
the NG and HT groups $(P<$ 0.05); however, after $72 \mathrm{~h}$ of NG treatment, there was no difference in the expression of set7/9 mRNA between the groups $(P>0.05)$ (Fig. 2).

Transient HG stimulation induces sustained $\mathrm{H} 3 \mathrm{~K} 4$ monomethylation

The expression of H3K4me1 in mesangial cells was detected by western blot analysis. The results showed that HG treatment for $24 \mathrm{~h}$ induced the upregulation of $\mathrm{H} 3 \mathrm{~K} 4$ monomethylation; meanwhile, this upregulated H3K4 monomethylation was sustained for at least $48 \mathrm{~h}$. However, there was no difference between the HT and NG groups (Fig. 3).

Transient HG stimulation upregulates the expression of $N F-\kappa B$ p 65 mRNA

Due to histone methylation,monomethylation of H3K4 could free target genes from the repression of histone complexes. Therefore, we examined the expression of NF- $\kappa \mathrm{B}$ p65 mRNA to identify the consequence of $\mathrm{H} 3 \mathrm{~K} 4$ monomethylation. The expression of NF- $\kappa$ B p65 mRNA was upregulated in mesangial cells for $72 \mathrm{~h}$ in the

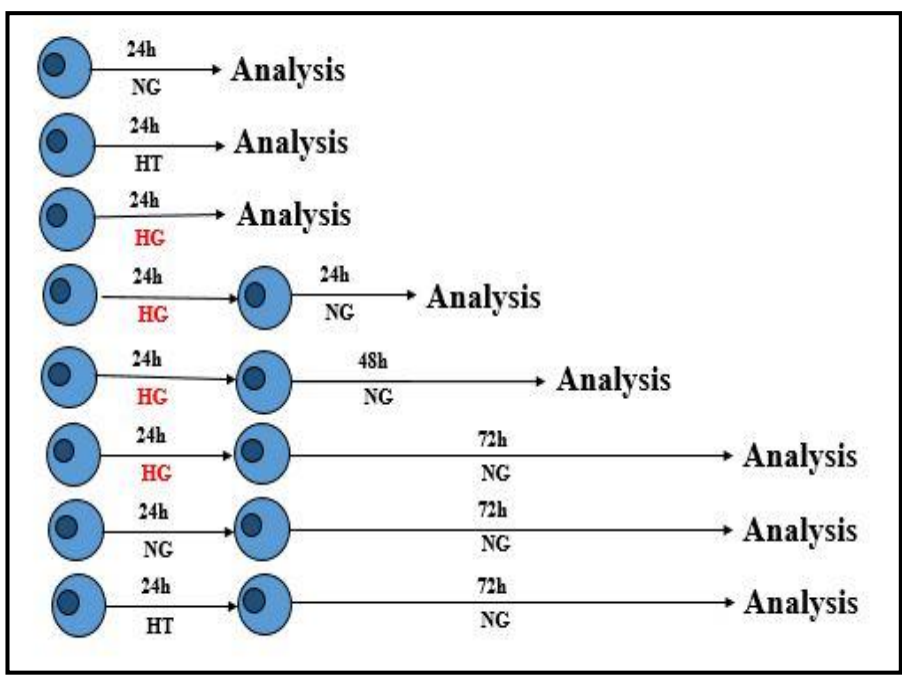

Fig. 1. Schematic representation of experimental model.

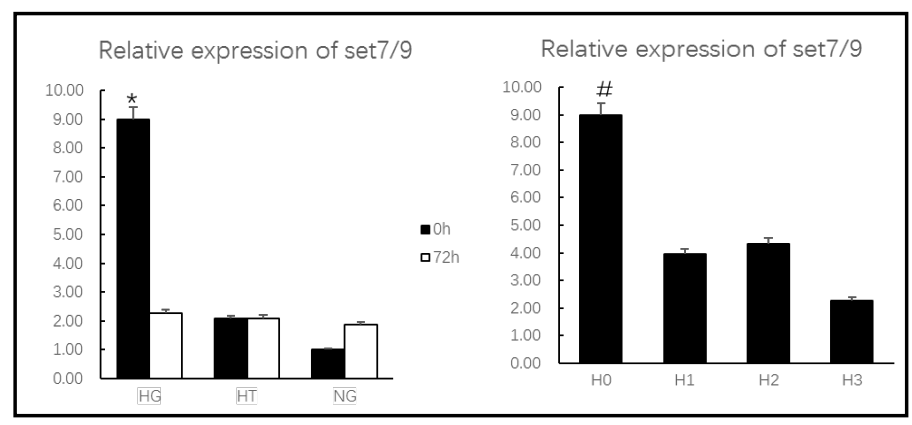

Fig. 2. Transient HG stimulation upregulates the expression of set7/9 mRNA. *Compared with the HT and NG groups, $\mathrm{P}<0.05$. "Compared with the NG culture condition that lasted for 24,48 , and $72 \mathrm{~h}, \mathrm{P}<0.05$. [HG high glucose group, HT hypertonic group, NG normal glucose group, H0 high glucose treatment for $24 \mathrm{~h}, \mathrm{H} 1 \mathrm{high}$ glucose treatment for $24 \mathrm{~h}$ and then normal glucose treatment for $24 \mathrm{~h}, \mathrm{H} 2$ high glucose treatment for $24 \mathrm{~h}$ and then normal glucose treatment for $48 \mathrm{~h}, \mathrm{H} 1$ high glucose treatment for $24 \mathrm{~h}$ and then normal glucose treatment for $72 \mathrm{~h}]$. HG group, and even after $72 \mathrm{~h}$ of NG culture (Fig. 4).

\section{Upregulation of inflammatory factors after transient HG stimulation}

To investigate the effect of the upregulation of NF- $\mathrm{kB}$ p65, an enzyme-linked immunosorbent assay was used to examine the expression of related inflammatory factors, that is, MCP- 1 and VCAM-1. The results showed that MCP- 1 and VCAM-1 were upregulated in the supernatant of the HG group under the NG condition that followed (Fig. 5). 


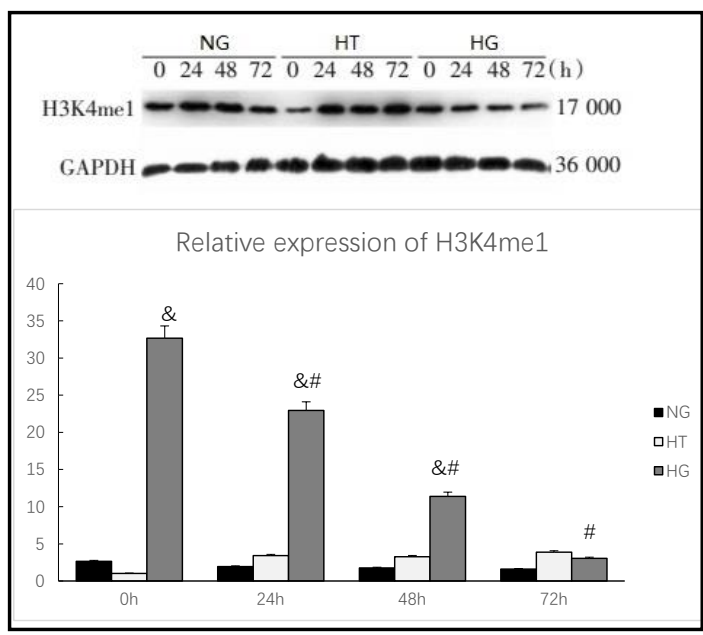

Fig. 3. Relative expression of H3K4me1. ${ }^{\&}$ Compared with the HT and NG groups at the same time, $\mathrm{P}<0.01 .{ }^{\#}$ Compared with the $\mathrm{HG}$ group at $0 \mathrm{~h}$, $\mathrm{P}<0.01 ; \mathrm{n}=3$.

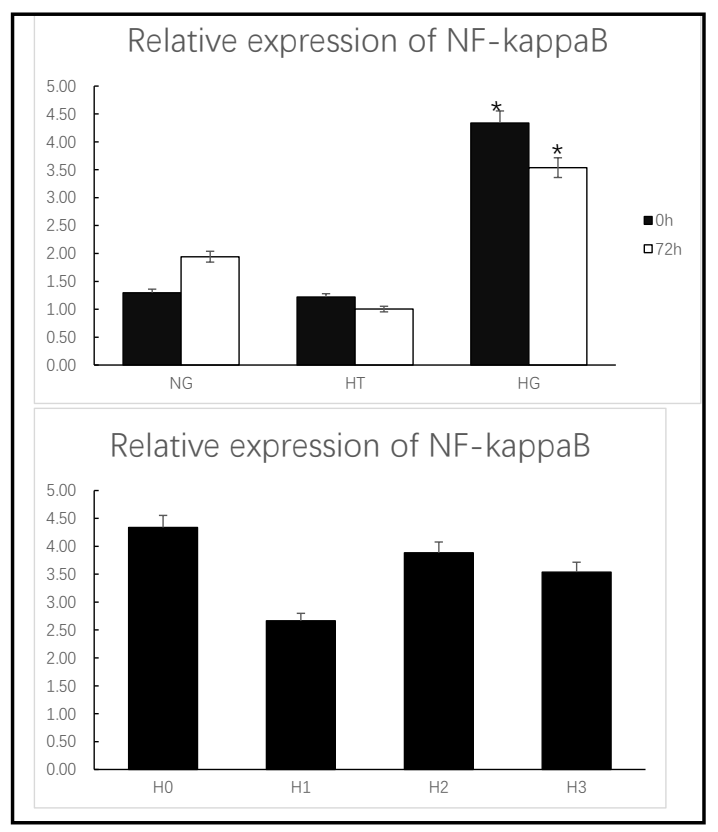

Fig. 4. Relative expression of NF- $\kappa \mathrm{B} .{ }^{*}$ Compared with the HT and NG groups at the same time, $\mathrm{P}<0.01$. In the $\mathrm{HG}$ treatment group, the expression of NF- $\kappa B$ was increased, $\mathrm{P}>0.01$.

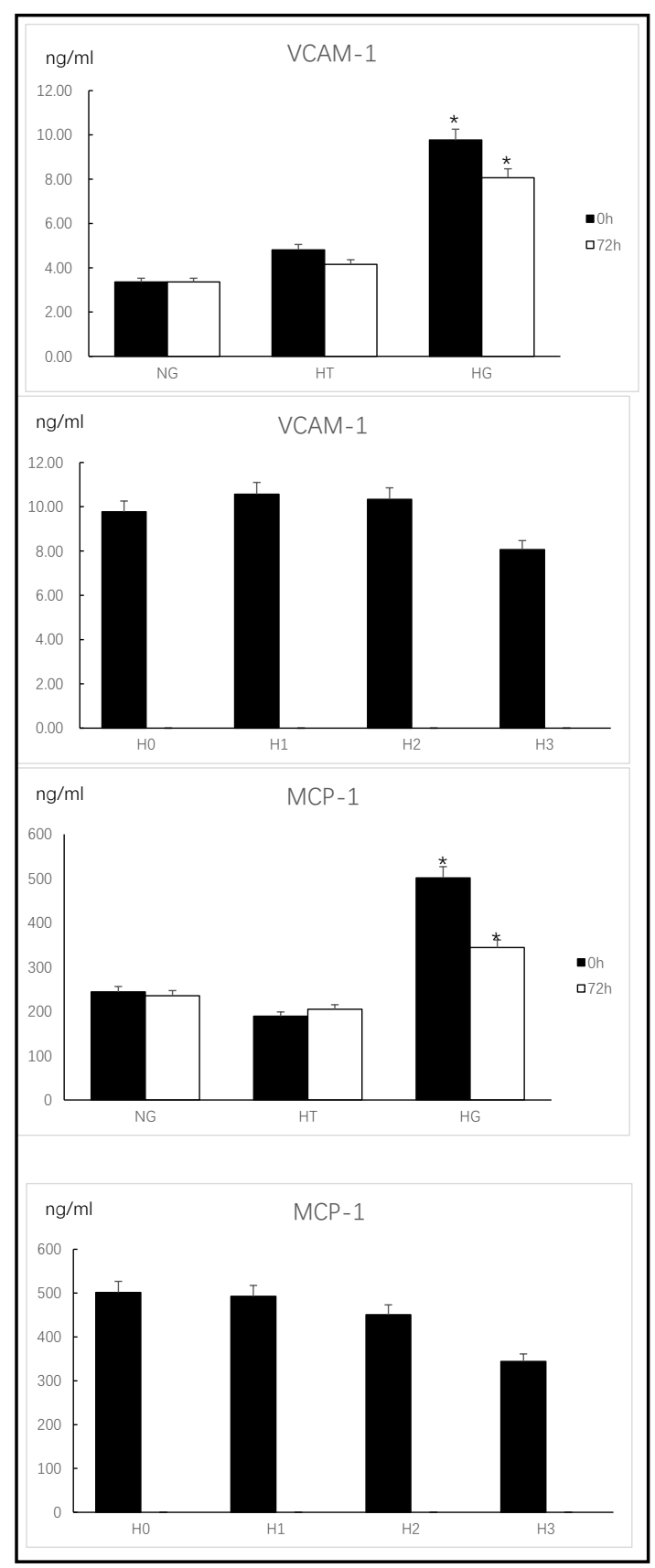

Fig. 5. Expression of VCAM-1 and MCP- $1{ }^{*}$ Compared with the NG group and HT group, $\mathrm{P}<0.01$. In the HG group, VCAM-1 and MCP-1 expression was increased, $\mathrm{P}>0.01$.

\section{Discussion}

It has been proven that hyperglycemic conditions can induce a series of pathological changes in the kidney that cannot be reversed at the present time. Therefore, the main strategy to prevent such pathological changes is to control glycemia. Thus, the main preventive measures for diabetic complications are controlling glycemia, blood pressure, 


\section{Cellular Physiology Cell Physiol Biochem 2018;49:1747-1754

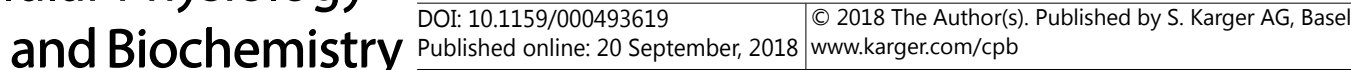 \\ Yunlei et al.: Transient High Glucose Induces Sustained Inflammation}

and blood lipids at physiological levels. Under strict glycemic control, however, a subset of diabetic patients can still develop irreversible DN. In the present study, we showed that the transient exposure of rat renal mesangial cells to a HG condition could induce persistent epigenetic changes in the promoter region of the NF- $\mathrm{kB}$ p65 gene. These epigenetic changes were sustained for no less than $48 \mathrm{~h}$; however, the upregulated expression of NF- $\mathrm{BB}$ p65 subunit-target inflammatory factors, namely, MCP-1 and VCAM-1, persisted for more than $72 \mathrm{~h}$.

It has been demonstrated that transient hyperglycemia causes the persistent recruitment of the histone methyltransferase set7/9 and increased H3K4 monomethylation in the proximal NF- $\mathrm{BB}$ promoter, leading to the exposure of p65 in the DNA fragment wrapped on histone and the subsequent upregulation of related genes [13]. Our findings indicate that HG stimulation for $24 \mathrm{~h}$ could upregulate the translation of set $7 / 9$, which is consistent with the monomethylation of H3K4, in rat renal mesangial cells. When the cells were subsequently transitioned to NG medium, the upregulated expression of set7/9 was sustained for more than $48 \mathrm{~h}$; however, the upregulation of H3K4 monomethylation was sustained for more than $72 \mathrm{~h}$. The reason for this observation might be that the inhibition of the related histone demethylase in the HG condition was resolved in the NG condition, and demethylation was delayed for approximately $24 \mathrm{~h}$. It has been demonstrated that transient HG (16 h) stimulation can induce a transient upregulation in H3K4me1 expression in mouse aortic endothelial cells, which is consistent with our results. In a previous study, the set7/9 gene was knocked down, and transient HG stimulation could not induce the upregulation of H3K4me1 [14].

MCP-1 is a small cytokine that belongs to the CC chemokine family. It recruits monocytes, memory T cells, and dendritic cells to the sites of inflammation produced by either tissue injury or infection $[15,16]$. VCAM-1 protein mediates the adhesion of lymphocytes, monocytes, eosinophils, and basophils to the vascular endothelium. It also functions in leukocyte-endothelial cell signal transduction [17]. Both of these chemokines play a vital role in early inflammation. Acting as an important inflammatory signaling pathway, NF- $\kappa \mathrm{B}$ mediates the pathogenesis and prognosis of DN [18-20]. In addition, the NF- $\kappa B$ p65 subunit is upregulated in circulating monocytes, renal tubular epithelium of diabetic patients, and mouse aortic endothelial cells [21, 22]. In our study, $24 \mathrm{~h} \mathrm{HG}$ stimulation could upregulate the expression of NF- $\kappa$ B p65 and the related proinflammatory factors MCP-1 and VCAM-1. These results indicate that transient HG stimulation can activate the inflammatory pathway and release inflammatory factors under the NG condition that followed.

\section{Conclusion}

Our study shows that transient HG stimulation can induce the expression of the histone methyltransferase set7/9 and H3K4 monomethylation, and this upregulation could be sustained for more than $48 \mathrm{~h}$ in renal mesangial cells. In addition, the expression of NF- $\mathrm{KB}$ p65, MCP-1, and VCAM-1 was also upregulated. These findings suggest that a HG "memory" can induce a sustained inflammatory effect via an epigenetic mechanism.

\section{Acknowledgements}

This study was supported by grants from the National Natural Science Foundation of China (81270808), National Science Foundation of Liaoning Province (201602821), Liaoning Province Higher Education Major Science and Technology Platform Skin Immune Disease Science Key Laboratory of Independent Innovation Fund Project (201303), and Science and Technology Project of Shenyang (F16-205-1-40). 


\section{Cellular Physiology Cell Physiol Biochem 2018;49:1747-1754 and Biochemistry \begin{tabular}{l|l} 
DOI: 10.1159/000493619 & $\begin{array}{l}\text { (c) } 2018 \text { The Author(s). Published by S. Karger AG, Basel } \\
\text { www.karger.com/cpb }\end{array}$
\end{tabular} \\ Yunlei et al.: Transient High Glucose Induces Sustained Inflammation}

\section{Disclosure Statement}

The authors declare that there are no conflict of interests.

\section{References}

1 KDOQI: KDOQI Clinical Practice Guidelines and Clinical Practice Recommendations for Diabetes and Chronic Kidney Disease. Am J Kidney Dis 2007;49:S12-154.

-2 Tuttle KR, Bakris GL, Bilous RW, Chiang JL, de Boer IH, Goldstein-Fuchs J, Hirsch IB, Kalantar-Zadeh K, Narva AS, Navaneethan SD, Neumiller JJ, Patel UD, Ratner RE, Whaley-Connell AT, Molitch ME: Diabetic kidney disease: a report from an ADA Consensus Conference. Am J Kidney Dis 2014;64:510-533.

-3 Ding T, Chen W, Li J, Ding J, Mei X, Hu H: High Glucose Induces Mouse Mesangial Cell Overproliferation via Inhibition of Hydrogen Sulfide Synthesis in a TLR-4-Dependent Manner. Cellular physiology and biochemistry: international journal of experimental cellular physiology, biochemistry, and pharmacology 2017;41:1035-1043.

4 Cahill GF, Jr: Metabolic memory. N Engl J Med 1980;302:396-397.

-5 Writing Team for the Diabetes C, Complications Trial/Epidemiology of Diabetes I, Complications Research G: Effect of intensive therapy on the microvascular complications of type 1 diabetes mellitus. JAMA 2002;287:2563-2569.

-6 Writing Team for the Diabetes C, Complications Trial/Epidemiology of Diabetes I, Complications Research G: Sustained effect of intensive treatment of type 1 diabetes mellitus on development and progression of diabetic nephropathy: the Epidemiology of Diabetes Interventions and Complications (EDIC) study. JAMA 2003;290:2159-2167.

7 The relationship of glycemic exposure (HbA1c) to the risk of development and progression of retinopathy in the diabetes control and complications trial. Diabetes 1995;44:968-983.

8 Kim ES, Isoda F, Kurland I, Mobbs CV: Glucose-induced metabolic memory in Schwann cells: prevention by PPAR agonists. Endocrinology 2013;154:3054-3066.

-9 Zhong Q Kowluru RA: Epigenetic modification of Sod2 in the development of diabetic retinopathy and in the metabolic memory: role of histone methylation. Invest Ophthalmol Vis Sci 2013;54:244-250.

-10 Villeneuve LM, Reddy MA, Lanting LL, Wang M, Meng L, Natarajan R: Epigenetic histone H3 lysine 9 methylation in metabolic memory and inflammatory phenotype of vascular smooth muscle cells in diabetes. Proc Natl Acad Sci U S A 2008;105:9047-9052.

11 Villeneuve LM, Natarajan R: The role of epigenetics in the pathology of diabetic complications. Am J Physiol Renal Physiol 2010;299:F14-25.

12 Hou B, Qiang G, Zhao Y, Yang X, Chen X, Yan Y, Wang X, Liu C, Zhang L, Du G: Salvianolic Acid A Protects Against Diabetic Nephropathy through Ameliorating Glomerular Endothelial Dysfunction via Inhibiting AGE-RAGE Signaling. Cellular physiology and biochemistry: international journal of experimental cellular physiology, biochemistry, and pharmacology 2017;44:2378-2394.

-13 Nishioka K, Chuikov S, Sarma K, Erdjument-Bromage H, Allis CD, Tempst P, Reinberg D: Set9, a novel histone $\mathrm{H} 3$ methyltransferase that facilitates transcription by precluding histone tail modifications required for heterochromatin formation. Genes Dev 2002;16:479-489.

14 El-Osta A, Brasacchio D, Yao D, Pocai A, Jones PL, Roeder RG, Cooper ME, Brownlee M: Transient high glucose causes persistent epigenetic changes and altered gene expression during subsequent normoglycemia. J Exp Med 2008;205:2409-2417.

15 Deshmane SL, Kremlev S, Amini S, Sawaya BE: Monocyte chemoattractant protein-1 (MCP-1): an overview. J Interferon Cytokine Res 2009;29:313-326.

-16 Tesch GH: MCP-1/CCL2: a new diagnostic marker and therapeutic target for progressive renal injury in diabetic nephropathy. Am J Physiol Renal Physiol 2008;294:F697-701.

-17 Cook-Mills JM, Marchese ME, Abdala-Valencia H: Vascular cell adhesion molecule-1 expression and signaling during disease: regulation by reactive oxygen species and antioxidants. Antioxid Redox Signal 2011;15:1607-1638. 


\section{Cellular Physiology Cell Physiol Biochem 2018;49:1747-1754

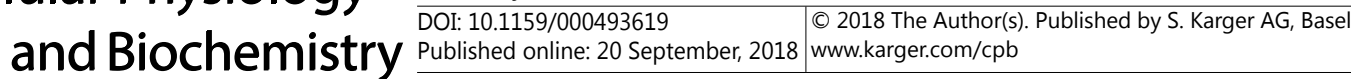 \\ Yunlei et al.: Transient High Glucose Induces Sustained Inflammation}

18 Malik S, Suchal K, Khan SI, Bhatia J, Kishore K, Dinda AK, Arya DS: Apigenin ameliorates streptozotocininduced diabetic nephropathy in rats via MAPK-NF-kappaB-TNF-alpha and TGF-beta1-MAPK-fibronectin pathways. Am J Physiol Renal Physiol 2017;313:F414-F422.

19 Kim SM, Lee SH, Kim YG, Kim SY, Seo JW, Choi YW, Kim DJ, Jeong KH, Lee TW, Ihm CG, Won KY, Moon JY: Hyperuricemia-induced NLRP3 activation of macrophages contributes to the progression of diabetic nephropathy. Am J Physiol Renal Physiol 2015;308:F993-F1003.

20 Ka SM, Yeh YC, Huang XR, Chao TK, Hung YJ, Yu CP, Lin TJ, Wu CC, Lan HY, Chen A: Kidney-targeting Smad7 gene transfer inhibits renal TGF-beta/MAD homologue (SMAD) and nuclear factor kappaB (NF-kappaB) signalling pathways, and improves diabetic nephropathy in mice. Diabetologia 2012;55:509-519.

21 Lewis P, Stefanovic N, Pete J, Calkin AC, Giunti S, Thallas-Bonke V, Jandeleit-Dahm KA, Allen TJ, Kola I, Cooper ME, de Haan JB: Lack of the antioxidant enzyme glutathione peroxidase-1 accelerates atherosclerosis in diabetic apolipoprotein E-deficient mice. Circulation 2007;115:2178-2187.

22 Bierhaus A, Schiekofer S, Schwaninger M, Andrassy M, Humpert PM, Chen J, Hong M, Luther T, Henle T, Kloting I, Morcos M, Hofmann M, Tritschler H, Weigle B, Kasper M, Smith M, Perry G, Schmidt AM, Stern DM, Haring HU et al.: Diabetes-associated sustained activation of the transcription factor nuclear factor-kappaB. Diabetes 2001;50:2792-2808. 